NBER WORKING PAPER SERIES

ON VARIABLE CAPITAL UTILIZATION

AND INTERNATIONAL 'TRADE THEORY

Lars E.O. Svensson

Working Paper No. 992

NATIONAL BUREAU OF ECONOMIC RESEARCH

1050 Massachusetts Avenue

Cambridge MA 02138

September 1982

The research reported here is part of the NBER's research program in International Studies. Any opinions expressed are those of the author and not those of the National Bureau of Economic Research. 


\section{On Variable Capital Utilization and International Trade Theory}

\section{ABSTRACT}

The paper makes two points as to how standard international trade theory is modified when an endogenous degree of capital utilization is introduced. The first point is that, if capital utilization during a period is less than full because of an exogenous time-dependent variation in productivity within the period, there is no modification of the standard theory. In particular, there is no need to adjust capital-intensity estimates according to the degree of capital utilization. This is in contrast to what has been argued in the literature. The other point is that, if capital utilization is less than full because of higher wages during part of the period, the night of a day and night, say, the required modification of trade theory is that of introducing several kinds of labor and endogenous labor supply, or, equivalently, of introducing nontraded goods.

Lars E.O. Svensson

National Bureau of Economic Research 1050 Massachusetts Avenue Cambridge, Massachusetts 02138

(617) $868-3900$

and

Institute for International

Economic Studies

University of Stockholm

S-10691 Stockholm, Sweden 
ON VARIABLE CAPITAL UTILIZATION AND INTERNATIONAL TRADE THEORY*

Lars E.0. Svensson

National Bureau of Economic Research, Cambridge, MA, and Institute for International Economic Studies, University of Stockholm.

\section{Introduction}

The degree of capital utilization, appearing for instance as the number of shifts working, varies considerably between sectors and countries. ${ }^{1}$ Recently, there has been some work on how different degrees of capital utilization would modify the standard international trade theory. ${ }^{2}$ For instance, Winston (1979) argues that the usual way of measuring factor intensities in Leontief-type tests of the Heckscher-Ohlin theory is wrong. Instead of just taking capital stock per manyear, or capital stock per employee, one should adjust the factor intensities for the degree of capital utilization. Then, given the considerable variance in capital utilization between sectors, the errors in the usual measurements might be large, and Winston argues that they may Indeed explain the Leontief Paradox.

In this paper, I wish to make two points as to how standard international trade theory is modified when an endogenous degree of capital utilization is introduced. The two points refer to two polar extreme assumptions concerning the source of the endogenous degree of capital utilization. The first point refers to the extreme situation when the degree of capital utilization during a period may be less than full, not because wages or other factor prices are higher during part of the period, but because there is, for some reason, a time-dependent variation in a firm's (or an industry's) technical productivity during the period. As an example, we can think of a fishing industry where the productivity of a given number of fishermen and boats are subject to seasonal fluctuations during the period, a year say, because the availability of fish varies exogenously during the period.

Under these circumstances we show that the firm's production per period can be considered to be a function $\mathrm{f}(\mathrm{K}, \mathrm{L}, \mathrm{u})$, of its capital stock, $\mathrm{K}$, labor input during the period, L, and the degree of capital utilization, $u$. It follows that the behavior 
of a profit maximizing firm can then be described as a two-stage procedure. In the first stage, the firm, for each capital stock and labor input, simply chooses the output-per-period maximizing degree of capital utilization, $u *(K, L)$. This results in an "indirect" production function $F(K, L)=f(K, L, u *(K, L))$. In the second stage, for given factor prices, i.e., capital rental and wage rate, the firm chooses the optimal level of capital stock $K$ and labor input $L$ so as to maximize profits, subject to the indirect production function. To the extent the indirect production function is a well-behaved neoclassical production function, it is clear that the whole standard Heckscher-ohlin trade theory applies. In particular, it is clear that the relevant factor intensity is $K / L$, capital stock over labor input, and not $u * K / L$, Winston's adjusted capital intensity.

The second point refers to the other extreme situation, when different capital utilization is due, not to any time-dependent variation in productivity during the period, but to a variation in wages within the period. For concreteness, let the period be a day and night, i.e., 24 hours, and let the night wage be higher than the day wage. The wage differential between day and night time labor then reflects workers' relative preferences between working day and working night. Many examples of ordinary manufacturing industries would seem to correspond to this case.

It is argued below that day and night labor should then be regarded as different factors. Hence, this situation differs from the standard $2 \times 2$ Heckscher-Ohlin case in that there are three factors rather than two, namely capital, day labor, and night labor. Furthermore, to make endogenous the total capital utilization in an economy, night labor (or both kinds of labor) should be in variable supply, which is formally equivalent to introducing production and consumption of non-traded goods.

Thus, the modifications of the trade theory which follow from introducing variable capital utilization with a wage premium on overtime are thus exactly those that follow from the introduction of more than two factors of production and of non-traded goods. Once this is realized, the existing results on these modifications in the trade litera- 
ture can hence, suitably interpreted, be directly applied to the variable capital utilization case.

The first point is developed in Section 2, and the second in Section 3. Section 4 presents some conclusions.

\section{Constant wages through period}

Let the period be denoted by the unit interval, $0 \leq t \leq 1$. Consider a firm, whose technology is described by the instantaneous production function $g(k(t), l(t), t)$, which gives the instantaneous flow of output at time $t$ as a function of the instantaneous flow of capital services, $k(t)$, and labor services, $l(t)$, at $t$ ime $t$. Let the instantaneous production function be a well-behaved neoclassical production function of $k(t)$ and $l(t), 3$ and assume that the productivity of capital and labor services is decreasing over time within the period, i.e., $g_{t} \leq 0$.

Let the firm own the capital stock $\mathrm{K}$, and let one unit of capital stock, when used, give rise to one unit of instantaneous capital services. Assume that for technological reasons the flow of labor services is constant when the firm produces. ${ }^{4}$ The firm will produce only during the subperiod $0 \leq t \leq u$, where $u, 0 \leq u \leq 1$, denotes the degree of capital utilization. Let $L=\int_{0}^{1} \ell(t) d t$ denote labor (services) input per period. It follows that the instantaneous flows of capital and labor services fulfill

$$
k(t)=\begin{aligned}
& K \text { for } 0 \leq t \leq u, \\
& 0 \text { for } u<t \leq 1,
\end{aligned} \quad \text { and } \quad l(t)=\quad L / u \text { for } 0 \leq t \leq u,
$$

Production per period will be a function, $f(K, L, u)$, of the capital stock, the labor input per period, and the degree of capital utilization, defined by

$$
f(K, L, u)=\int_{0}^{u} g(K, L / u, t) d t .
$$

The indirect production function, $F(K, L)$, will be given by

$$
F(K, L)=\max \{f(K, L, u): 0 \leq u \leq I\}=f(K, L, u *(K, L)) \text {, }
$$

where $u^{*}(K, L)$ denotes the optimal degree of capital utilization.

If the instantaneous production function is a well-behaved neoclassical product $\dot{1}$... function, so is the production-per-period function $f(K, L, u)$ for given $u$. Then $1 t$ 
can be shown that the indirect production function $F(K, L)$ also is a well-behaved neoclassical production function.

Let us consider a special case: Let the instantaneous production function be $g(k(t), \ell(t), t)=(1-t)(k(t))^{\alpha}(\ell(t))^{1-\alpha}, 0<\alpha<1$. That is, it is a Cobb-Douglas function in $k(t)$ and $\ell(t)$, and productivity decreases 1 inearily. It follows from (2) that

$$
f(K, L, u)=\int_{0}^{u}(1-t) d t K^{\alpha}(L / u)^{1-\alpha}=A(u) K^{\alpha} L^{1-\alpha}
$$

where $A(u)=\left(u^{\alpha}-u^{\alpha+1} / 2\right)$. The optimal degree of capital utilization, $u^{*}$, maximizes $A(u)$ and hence fulfills the first order condition $\alpha\left(u^{*}\right)^{\alpha-1}-(\alpha+1)\left(u^{*}\right)^{\alpha / 2}=\left(u^{*}\right)^{\alpha-1}(\alpha-$ $\left.(\alpha+1) u^{*} / 2\right)=0$, which implies $u^{*}=2 \alpha /(1+\alpha)$. In this case the optimal degree of capital utilization is independent of the capital stock and labor input. The indirect production function is

$$
F(K, L)=A\left(u^{*}\right) K^{\alpha} L^{1-\alpha},
$$

which is Cobb-Douglas in capital stock and labor input.

Assume that the wage, $w$, is the same during the period. For a given rental per capital good per period, $r$, and a given price of output, $p$, we clearly get the standard neoclassical profit maximizing problem, $\max \mathrm{pF}(\mathrm{K}, \mathrm{L})$ - rK - wL, where output is given by the indirect production function. In particular, the relevant factor intensity is $\mathrm{K} / \mathrm{L}$, the unadjusted capital stock over labor services per period. It is not Winston's adjusted $u * K / L$, accumulated capital services per period over labor input per period, which equals instantaneous capital intensity $k(t) / \ell(t)$ during production.

\section{Higher wages during the night}

For concreteness, let the period be a day and night, 1.e., 24 hours. Consider a firm that can operate with the same technology during the day as during the night. This is, the firm is not subject to any variation in technical productivity during the day and night. It however faces one wage rate during the day, and another (higher) wage rate during the night. Let it own a capital stock $K$, and let $L$ and $N$ denote labor input during the day and the night, respectively. Production per day will be 
given by $f(K, L)$, a well-behaved neoclassical production function. Production per night is $f(K, N)$. Hence, production per day and night is given by

$F(K, L, N)=f(K, L)+f(K, N)$.

Let $w$ denote the day wage per day, and let $s$ denote the night wage per night. Profits per day and night will be given by $\pi=p F(K, L, N)$ - rK - wL - sN. Assume that the firm can choose one factor intensity during the day and another during the night. Then, for a given capital stock, the profit maximizing day labor input and night labor input, $\mathrm{L}(\mathrm{w} / \mathrm{p}, \mathrm{K})$ and $\mathrm{N}(\mathrm{s} / \mathrm{p}, \mathrm{K})$, are given by the equality of marginal product and the product wage,

$$
f_{L}(K, L)=w / p \text { and } f_{N}(K, N)=s / p \text {. }
$$

The two labor input levels can be illustrated in a familiar way in Fig. 1:

\section{Fig. 1}

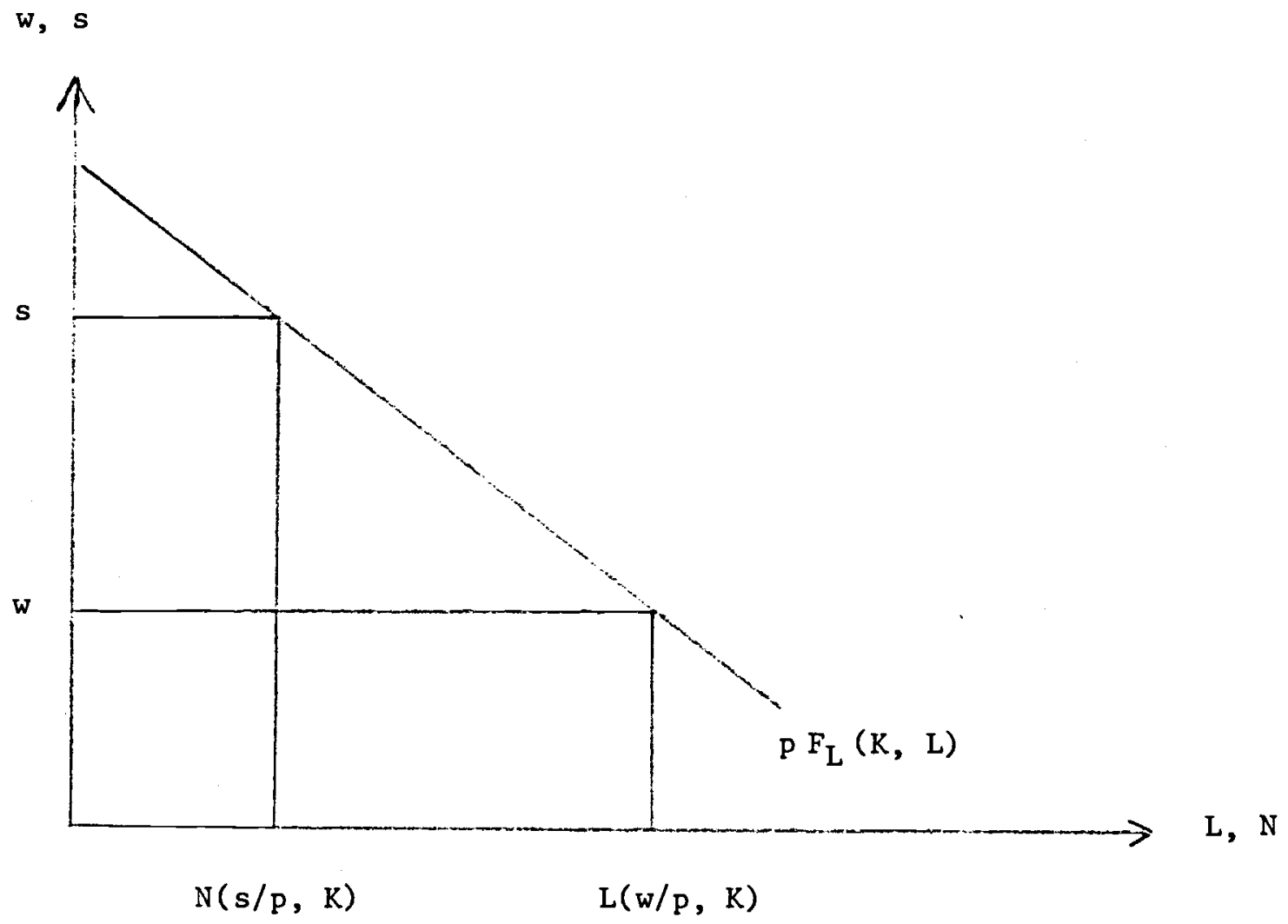

It is obvious, that from the point of view of the firm, as long as day and night wages differ, day and night labor are different factors. It is also clear that, if a higher night wage reflects workers' relative preference against working nights, day and 
night labor cannot be perfect substitutes from the point of view of workers, and are hence different factors also from the supply side. Furthermore, to make endogenous the total capital utilization in an economy, day and night labor cannot both be fixed in supply. We conclude that a proper treatment of these issues requires the introduction of variable supply of labor.

It is clear that a model of an open economy incorporating these aspects would differ from the standard $2 \times 2$ Heckscher-Ohl in model of a small country in two respects. First, it has two different kinds of labor, in addition to capital. Hence, there are three primary factors instead of the standard two. Second, the supply of one of the labors is variable rather than fixed. Formally, introducing variable supply of labor in a Heckscher-Ohlin model is identical to introducing non-traded goods. This is so, since leisure can be interpreted as a non-traded good.

\section{Conclusions}

First we have looked at the extreme situation when a variable degree of capital utilization results solely from a technical variation of productivity within the period and not from variations in wages. We have found that the behavior of the firm can then be represented by an indirect production function of capital stock and labor input per period, where the degree of capital utilization is chosen optimally and hence does not appear in the indirect production function. For given factor prices the firm then chooses capital stock and labor input per period so as to maximize profit per period.

The conclusions are straightforward: If the indirect production function is wellbehaved, the standard Heckscher-Ohlin theory applies directly. If it is not, the standard theory does not apply. With regard to empirical work, in the former case the relevant factor intensity is capital stock over labor input per period, without any adjustment according to the degree of capital utilization. In the latter case, the question of which factor intensity is relevant may not be meaningful.

In the other extreme situation, the variable capital utilization is the result of different day and night wages, and not of any technical variation of productivity 
between day and night. The difference in day and night wages is due to workers' relative preference for working day rather than night. Both for firms and workers, day and night labor are not perfect substitutes but different factors. The required modification of the standard trade theory is that of introducing more than one kind of labor, at least one of which is in variable supply and hence enters workers' utility functions. As is well known, this is exactly analogous to introducing production of non-traded goods in trade models. The results in the existing literature on problems with non-traded goods can then, suitably interpreted, be applied to the case of variable capital utilization.

In this other extreme situation, what are the conclusions relevant to empirical work? Rigorously, day and night labor should be regarded as different factors. In most empirical work in the trade literature there is aggregation of heterogenous kinds of labor into one labor input (or a few labor inputs). In that context, the error in aggregating day and night labor may be relatively small. Hence, in less rigorous empirical work, the relevant factor intensity may again be capital stock over total labor input per period, the latter aggregate including both day and night labor. Again, there is no adjustment of the capital stock according to its degree of utilization. 6 The other alternative is to explicitly disaggregate labor into day and night labor.

\section{Footnotes}

*. Comments on previous versions by Harry Flam, Carl Hamilton, Elhanan Helpman, Henrik Horn, and Gordon Winston are gratefully acknowledged. The usual caveat applies.

1. See Winston for references to empirical studies.

2. Winston, and several recent unpublished papers by $R$. Betancourt, $C$. Clague, and A. Panagariya, University of Maryland.

3. That is, having constant returns to scale and being concave, with $g_{k}, g_{\ell}>0$ and $g_{k k}, g_{\ell \ell}<0$. Subindices will denote partials throughout the paper.

4. We thus assume that the firm chooses the instantaneous capital services/labor services ratio, $k(t) / \ell(t)$, subject to the technological constraint that the rat , must remain the same during the period of production. 
5. We note that we have an inner solution, $0<u^{*}<1$.

6. Suppose that workers' marginal rate of substitution of day labor for night labor is constant and equal to $1+\beta$, where $\beta$ is a positive constant. In an equilibrium the day and night wages would fulfill $s=(1+\beta) w$, that is, there is a constant (proportional) premium $\beta$ on night labor. From the point of view of firms, the relative price between day and night labor is constant. Hence, a composite Hicks aggregate labor $M=L+(1+\beta) N$ can be constructed with the indirect production function $G(K, M)=\max \{F(K, L, N): M=L+(I+\beta) N\}$. The wage rate corresponding to the labor composite is $w$, and the firm will maximize $\mathrm{pG}(\mathrm{K}, \mathrm{M})$ $\mathrm{rK}$ - wM. It is clear that the relevant factor intensity is $\mathrm{K} / \mathrm{M}$, capital stock over the labor composite.

We note that from the point of view of workers, we can also aggregate labor into a labor composite, with the same weights. The model essentially collapses into a one-labor model.

\section{$\underline{\text { Ref erences }}$}

Winston, G.C., 1979, On measuring factor proportions in industries with different seasonal and shift patterns, or did the Leontief Paradox ever exist? Economic Journal 89, 897-904. 